\title{
What are the effective ways to translate clinical leadership into health care quality improvement?
}

\author{
This article was published in the following Dove Press journal: \\ Journal of Healthcare Leadership \\ 4 February 2016 \\ Number of times this article has been viewed
}

\author{
Robert McSherry' \\ Paddy Pearce ${ }^{2}$ \\ 'School of Health and Social Care, \\ University of Teesside, Middlesbrough, \\ 2PKP Consulting, Yarm, United Kingdom
}

Correspondence: Robert McSherry School of Health and Social Care, University of Teesside, Middlesbrough, United Kingdom TSI 3BA

Email robert.mcsherry@tees.ac.uk

\begin{abstract}
The presence and/or absence of effective leaders in health care can have a stark consequence on the quality and outcomes of care. The delivery of safe, quality, compassionate health care is dependent on having effective clinical leaders at the frontline. In light of the Kirkup and Francis reports, this article explores some ways of translating clinical leadership into health care quality improvement. This is achieved by exploring what is clinical leadership and why and how this is important to health care quality improvement, clinical leadership, and a duty of candor, along with the importance clinical leadership plays in the provision of quality care improvement and outcomes. Clinical leaders are not predefined roles but emerge from the complex clinical setting by gaining an acquired expertise and from how they then internalize this to develop and facilitate sound relationships within a team. Clinical leaders are effective in facilitating innovation and change through improvement. This is achieved by recognizing, influencing, and empowering individuals through effective communication in order to share and learn from and with each other in practice. The challenge for health care organizations in regard to creating organizational cultures where a duty of candor exists is not to reinvent the wheel by turning something that is simple into something complex, which can become confusing to health care workers, patients, and the public. By focusing on the clinical leader's role and responsibilities we would argue they play a crucial and pivotal role in influencing, facilitating, supporting, and monitoring that this duty of candor happens in practice. This may be possible by highlighting where and how the duty of candor can be aligned within existing clinical governance frameworks.
\end{abstract}

Keywords: governance, candor, safety, outcomes

\section{Introduction}

Globally, health care organizations and their leaders and managers are facing huge challenges - financial, political, societal, and professional - to deliver high-quality care and services for less costs. Governance, performance and risk management systems and processes are all under enormous independent external scrutiny and review. ${ }^{1}$ Governments, regulators, commissioners, and professional bodies want to ensure health care organizations provide efficient and effective safe, quality care and services for their communities, populations, and health care workers.

The presence and/or absence of effective leaders in health care can have a stark consequence on the quality and outcomes of care. The delivery of safe, quality, and compassionate health care and services is dependent on having effective leaders at the frontline. Kirkup's Report of the Morecambe Bay Investigation ${ }^{2}$ and the public inquiry into the Mid Staffordshire National Health Service (NHS) Foundation Trust 
(known as the Francis report) $)^{3}$ located in England, United Kingdom scandals are two examples of where some leaders (and managers) failed in their accountability, role, and responsibility to care. The reports highlighted harmful and neglectful systemic failures in health care governance across numerous organizations to deliver, monitor, assure, and safeguard a culture of safety, quality, and compassionate care and services. The importance of promoting "strong and patient centred healthcare leadership" "was recommended and should be reinforced by leaders, or indeed, we would argue, everyone working in health care at all times.

More radical was the recognition and/or endorsement of the need for the establishment of a leadership college/ academy, accreditation/registration scheme, and review/ removal regulator for those individuals found "guilty of serious breaches of the code of conduct or otherwise found unfit for eligibility for leadership posts". 3

These recommendations may be highly radical, ambitious, and welcome. However, to materialize in the future, they will require significant debating by professional bodies, regulators, commissioners, politicians, educational establishments, and existing leadership and management providers along with a robust strategy, resourcing, and support. We would argue that the issue is not to have a knee-jerk response and action to these inquiries and reports. We would suggest that each health care organization and individual reviews and reflects upon the reports in order to learn from these regrettable situations.

In relation to leadership, it is important to acknowledge and recognize that in every health care organization and team and at an individual level there is always room for improvement(s). In parallel, it is important to acknowledge and recognize that improvements only come by affording opportunity and support for individuals and teams to develop. We would suggest that the challenge facing health care organizations in light of the Kirkup report ${ }^{2}$ and Francis report $^{3}$ is in reviewing the efficiency and effectiveness of existing organizations' leadership framework(s)/programs and/or in devising, implementing, and evaluating existing/ new leadership programs.

The authors acknowledge that there is an enormous amount of health care literature on the topic of leadership, leadership theory and/or frameworks, personality, behaviors, styles or traits, and competency. This is mirrored in the rising numbers of organizations, programs, and frameworks attempting to decipher and apply this to enable innovation, change, and improvements within health care. In essence, the vastness and variation on the topic is indicative of the challenges associated with defining leadership, differentiating leadership from management, and illuminating the core traits and competency required of a leader. Similarly, the importance and opportunities of embracing leadership and the benefits to individual and organizational performance, safety, quality, and care require recognition and reward.

\section{Aims and objectives}

The aim of this article is not to repeat or critically review the health care literature akin to identifying the opportunities and challenges of leadership identified in the Introduction section. ${ }^{1-3}$ In light of the Kirkup and Francis reports, the article explores some effective ways of translating clinical leadership into health care quality improvement. This is achieved by focusing on the following:

- What is clinical leadership and why and how this is important to health care quality improvement.

- An exploration of clinical leadership and a duty of candor.

- Highlighting the importance clinical leadership plays in the provision of quality care improvement and outcomes.

\section{What is clinical leadership and why and how is this important to health care quality improvement?}

Generally, leadership is both difficult and challenging to define because of the complexity of the term and its strong association and relationship with management. Field Marshal Slim ${ }^{4}$ suggests that:

[...] leadership is of the spirit, compounded of personality and vision; its practice is an art. Management is of the mind, a matter of accurate calculation [...] its practice is science. Managers are necessary; leaders are essential.

Similar to Slim ${ }^{4}$ the King's Fund Commission on Leadership and Management in the NHS 5 indicate that health care improvements and quality are dependent on the effectiveness of leaders and managers at all levels of health care. Like $\mathrm{Slim}^{4}$ and the King's Fund, ${ }^{5}$ we would suggest that both leaders and managers are essential in ensuring the delivery of safe, quality, and effective health care and services. We would also endorse the National Advisory Group on the Safety of Patients in England's statement that "leadership is about the mobilising the attention, resources and practice of others towards particular goals, values or outcomes". 6 Leadership is about listening and responding to people in order to maximize their potential in delivering safe, quality, and effective health care. ${ }^{7}$ 
Rosemary Kennedy, former chief nursing officer for Wales, cited in Frampton ${ }^{8}$ suggested that leadership is about getting the best from others - not 'simply telling staff you are their leader. ${ }^{8}$

We would argue that health care professionals, leaders, managers, educators, and researchers all play a vital and pivotal role in maximizing staffs' quest for excellence in health care. ${ }^{9}$ More fundamentally, health care

[...] organisations need to continue to deliver quality care, nurture innovation and improve productivity. The lynchpin for implementing and sustaining these changes is the quality of clinical leadership in practice. ${ }^{10}$

\section{Disentangling leadership and clinical leadership in health care}

A quick review of the characteristics and attributes of an effective leader ${ }^{4-10}$ and clinical leadership ${ }^{11-13}$ (Table 1) indicates that clinical leaders emerge from within the organization and clinical setting in which they work.

A review and synthesis of the works of Daly et al, the British Medical Association, and Stanley ${ }^{11-13}$ seems to suggest that clinical leaders are not predefined roles. They emerge from the complex clinical setting by having an acquired expertise, appropriate knowledge, and respect of their peers and from how they then internalize this to develop and facilitate sound relationships within a team. Clinical leaders need to be both affective and effective; affective is about making a difference; effective is associated with bringing about results through facilitating innovation and change through improvements within the clinical area. This is achieved by recognizing, influencing, and empowering individuals through effective communications in order to share and learn from and with each other in practice.
There are undoubtedly many similarities in characteristics and attributes of an affective and effective leader ${ }^{4-10}$ and clinical leader; ${ }^{11-13}$ these are outlined in Table 2.

In addition to those attributes and characteristics identified in Table 2, we would go a step further to argue that the personal qualities of an affective and effective clinical leader are associated with having self-belief, self-awareness, selfmanagement, a drive for improvement, and personal integrity. "Integrity", in this context, is associated with having inherent values and beliefs based on sound governance principles of honesty, openness, transparency, probity, and candor.

The empirical evidence demonstrating how affective and effective clinical leaders are in health care is relatively sparse. ${ }^{11}$ However, we would argue that clinical leaders, along with possessing the majority of the attributes and characteristics identified in Table 2, must be confident and competent with what sound governance principles mean and involve. This is because governance is and will remain a sound framework for assuring the standards and quality of care in practice.

Although we would argue that "integrated governance" is an ideal term for highlighting the interconnectedness and interdependency of the various systems and processes akin to quality improvement, performance, and outcomes, many clinical leaders continue to embrace clinical governance because it is directly related to practice offering a useful framework for the provision of quality care, ongoing improvement, and outcomes. Furthermore, clinical governance is defined by McSherry and Pearce as

[...] a robust framework that acknowledges the importance of adopting a culture of shared accountability for sustaining and improving the quality of services and outcomes for both patients and staff. ${ }^{14}$

Table I Definitions of clinical leadership

\begin{tabular}{|c|c|c|c|}
\hline Year & Authors & Definition & Keywords \\
\hline 2014 & Daly et al" & $\begin{array}{l}\text { "Clinical leadership is leadership provided by clinicians often recognised } \\
\text { as clinical leaders." }\end{array}$ & $\begin{array}{l}\text { - Practice } \\
\text { - Delivery } \\
\text { - Recognition }\end{array}$ \\
\hline 2012 & British Medical Association ${ }^{12}$ & $\begin{array}{l}\text { "Clinical leaders were perceived as doctors who had the vision to see } \\
\text { improvements to services or who were able to address limitations within the } \\
\text { health system and share their vision with their fellow doctors." }\end{array}$ & $\begin{array}{l}\text { - Vision } \\
\text { - Improvements } \\
\text { - Share } \\
\text { - Influence }\end{array}$ \\
\hline 2005 & Stanley ${ }^{13}$ & $\begin{array}{l}\text { "A clinician who is an expert in their field, and who, because they are approachable, } \\
\text { effective communicators and empowered, are able to act as a role model, } \\
\text { motivating others by matching their values and beliefs". }\end{array}$ & $\begin{array}{l}\text { - Expert } \\
\text { - Field } \\
\text { - Approachable } \\
\text { - Communicator } \\
\text { - Empowered } \\
\text { - Role model } \\
\text { - Motivator }\end{array}$ \\
\hline
\end{tabular}


Table 2 Similarities between leaders and clinical leaders

\begin{tabular}{l} 
- Visionary \\
- Communicator \\
- Facilitator \\
- Advocator \\
- Motivator \\
- Respectable \\
- Considerate \\
- Ethical \\
- Critical thinker \\
- A doer, evaluator \\
- Knowledgeable \\
- Tactful \\
- Trustworthy \\
- Credible style and approach \\
\hline
\end{tabular}

Note: Copyright $\odot$ 20I I. Reproduced from McSherry R, Pearce P. Clinical Governance: A Guide to Implementation for Healthcare Professionals. Oxford: Wiley-Blackwell Publishers; $2011 .{ }^{14}$

Similarly, McSherry and Haddock indicated that "clinical governance" is:

[...] ultimately, an umbrella term for all the issues and concepts that clinicians, non-clinicians, clinical leaders, mangers and board members know and foster, including standard setting, risk management, patient safety' to name but a few associated terms. ${ }^{15}$

Clinical governance supports clinical leaders to become affective and effective in providing and facilitating safe, quality care by drawing together the key concepts associated with patient safety, risk management, information and communication, accountability, and evidence-based practice, by:

- the systematic harmonization of clinical and managerial responsibilities with accountable practice;

- team working and interdependency through integrated working with and between health and social care in both the public and independent (private) sectors;

- monitoring, changing, evaluating, and improving practice to safeguard standards;

- the drive for constant quality improvement in all that they do;

- nurturing a health care organizational culture and working environment of continuous learning and sharing;

- placing a duty of care to improve individual, team, and organizational performance and outcomes; and

- adopting a person-centeredness approach in all that we do. ${ }^{14}$ The challenge facing clinical leaders in the ever-changing world of health care is recognizing and responding when improvements and change are required, along with adopting a facilitative people-centered approach to engage, encourage, enable, empower, and enlighten team members and patients/carers to become partners in the change and evaluative processes. Having a sound knowledge and understanding of the vision, values, and beliefs of the team and associated members along with their requirements to improve and/or maintain quality is imperative. Having this type of knowledge and understanding of the team can then be used to inform strategy ${ }^{16}$ and strategic planning ${ }^{17}$ with associated action plans.

\section{Clinical leadership and a duty of candor}

The Francis Report ${ }^{3}$ and the Health and Social Care Act 2008 (Regulated Activities) regulations $2014^{19}$ identified the need for developing a statutory duty of candor where a common health care organizational culture and working environment is established for safeguarding and protecting health care workers, patients/carers, and the public from harm. Three core characteristics were identified. "Openness": having the ability to speak up freely without fear of reprisal and retaliation when highlighting concerns and/or alternatively sharing and celebrating success. "Transparency": communicating and sharing information about performance and outcomes in a truthfully honest way with health care workers, patients, and the public. "Candor": ensuring that, in the unfortunate situation where a patient is harmed by a health care worker and/or health care service, they or their legal next of kin are informed of the full facts. This should be at the earliest possibly opportunity. An appropriate remedy should be afforded, wherein they are involved in any subsequent investigation/review that can facilitate learning and sharing. These stages of the process are essential in order to minimize recurrence of similar events; all this should occur regardless of a complaint and/or question raised regarding the situation. Where appropriate, a full apology should be offered and detailed records maintained.

The United Kingdom government and Department of Health, following the Francis report ${ }^{3}$ and publication of Hard Truths: The Journey of Putting Patients First ${ }^{18}$ has ensured that this is firmly stipulated in statutory regulation.

A health service body must act in an open and transparent way with relevant persons in relation to care and treatment provided to service users in carrying on a regulated activity. ${ }^{19}$

The challenge for health and social care organizations is not to reinvent the wheel or to make something that is simple into something complex and confusing to health care workers, patients, and the public. By focusing on the clinical leader's role and responsibilities, we would argue they play a crucial and pivotal role in influencing, facilitating, supporting, and monitoring that this duty of candor happens in practice. This may be possible by highlighting where and how the duty of candor can be aligned within existing governance frameworks. 
The importance of clinical leadership in ensuring sound governance principles and processes along with building a culture where candor exists is detailed in a self-assessment tool provided in Tables 3 and 4 . Table 3 provides a series of statements and rationale for aspiring clinical leaders to consider when establishing their readiness to embrace clinical leadership within the context of governance.

Table 3 was derived following a review of the literature ${ }^{4-16}$ where some fundamentally important attributes and characteristics associated with becoming an affective and effective clinical leader are offered. Table 3 is designed to develop your knowledge and understanding surrounding what constitutes an affective and effective clinical leader within the context of governance and duty of candor in the future. After reviewing Table 3, the completion of Table 4 is recommended.

Reviewing and completing Table 4 by ticking a "yes" to every question would indicate if an individual is well on their way to knowing and understanding some of the key facts and information associated with clinical leadership and governance. Ticking only a couple of boxes may indicate that the individual may require some dedicated time to explore and develop their knowledge, understanding, and

Table 3 Clinical leadership critical statements and rationale

\begin{tabular}{l} 
Number Statement \\
\hline $\begin{array}{l}\text { Affective and effective clinical leadership is dependent } \\
\text { knowing what clinical leadership is and what it involves } \\
\text { in practice. }\end{array}$ \\
Defining clinical leadership is highly challenging and a \\
complicated thing to do because it is linked to so many \\
of the core elements of safety, quality, and care. \\
3 Providing sound clinical leadership is an integral part \\
of every health care professional's codes of practice, \\
contracts of employment, professional accountability, \\
and roles and responsibility.
\end{tabular}

$4 \quad$ Clinical leadership is dependent on developing an honest, open, transparent, person-centered relationship between patients, carers, and significant others.

5 Sound clinical leadership is dependent on listening and responding to the experience of people and members of the team.

6 Effective clinical leadership involves teamworking, collaboration, and engagement with people.

$7 \quad$ The best way of establishing quality of care is through directly asking the patient, carer, and significant others in conjunction with those team members providing the care.

8 Affective and effective clinical leaders recognize that providing quality care and improvement is everyone's responsibility and does not happen in isolation.

9 Clinical leaders ensure and assure quality care is dependent on having sufficient support and resources from other leaders and managers.

10 Ensuring dignity with respect is regarded as an integral part of quality care and should be the number one priority of all clinical leaders.

\section{Rationale and relevance to the provision of quality care and governance}

To provide quality care, it is imperative that you are able to articulate and demonstrate what affective and effective clinical leadership involves and are able to highlight the impact your role and responsibility has on someone's health and well-being.

The provision of quality care is dependent on sound clinical leadership and management, effective team working, communication, and patient and user/carer participation and evaluation. Identifying and dealing with risks and having a robust system of information governance for accessing, recording, storing information, and record keeping is essential.

The provision of safe, quality, and compassionate care is not optional, but an integral part of everyone's contract of employment, roles and responsibility, and code of practice.

Ensuring the provision of safe patient care and challenging inadequate standards of care are essential.

The establishment of a holistic people-centered relationship to caring based on the principles of honesty, openness, and transparency with the patient, carer, users, the public, and professional colleagues is a major component of assuring patient safety and quality care. Clinical leadership is about listening, responding, and facilitating to achieve the best from individuals and services.

Effective communication is about listening and responding to feedback and informing the team members of the outcomes.

Demonstrating sound clinical leadership and developing integrated teamworking through engaging and involving the patient, carers, users, and various members of the team is a major part of delivering and establishing quality. Effective clinical leadership is about facilitating and collaborating with stakeholders to maximize the best outcomes. Affective and effective clinical leaders seek out the lived experience of patients, carers, and significant others in conjunction with the team. Demonstrating the outcomes of both provision and standards of care received by health care workers and patients/carers is imperative. Quality requires the involvement of the team and is everyone's responsibility.

Having and seeking the support from current leaders and managers is important in ensuring quality care.

Dignity with respect for all should always be provided and maintained.

Note: Adapted with permission from p.38 Table: 3.2 and p.39 Table: 3.3 from Ch.3 'Quality of Nursing Care' by Robert McSherry from "Care in nursing: Principles, Values and Skills" edited by McSherry W, McSherry R, Watson R. (2012); $2012 .{ }^{20}$ Copyright $\odot 2015$. By permission of Oxford University Press. 
Table 4 Clinical leadership checklist

\begin{tabular}{ll}
\hline Number & Statement \\
\hline 1 & Affective and effective clinical leadership is \\
dependent on knowing what clinical leadership \\
is and what it involves in practice. \\
Defining clinical leadership is highly challenging \\
and a complicated thing to do because it is \\
linked to so many of the core elements of \\
safety, quality, and care. \\
Providing sound clinical leadership is an integral \\
part of every health care professional's codes of \\
practice, contracts of employment, professional \\
accountability, and roles and responsibility. \\
Clinical leadership is dependent on developing \\
an honest, open, transparent, person-centered \\
relationship between patients, carers, and \\
significant others. \\
Sound clinical leadership is dependent on \\
listening and responding to the experience of \\
people and members of the team. \\
Effective clinical leadership involves \\
teamworking, collaboration, and engagement \\
with people. \\
The best way of establishing the quality of care \\
is through directly asking the patient, carer, \\
and significant others in conjunction with those \\
team members providing the care. \\
Affective and effective clinical leaders recognize \\
that providing quality care and improvement is \\
everyone's responsibility and does not happen \\
in isolation. \\
Clinical leaders ensure and assure quality care \\
is dependent on having sufficient support and \\
resources from other leaders and managers. \\
Ensuring dignity with respect is regarded as an \\
integral part of quality care and should be the \\
number one priority of all clinical leaders.
\end{tabular}

Note: Adapted with permission from p.38 Table: 3.2 and p.39 Table: 3.3 from Ch.3 'Quality of Nursing Care' by Robert McSherry from "Care in nursing: Principles, Values and Skills" edited by McSherry W, McSherry R, Watson R. (20I2). ${ }^{20}$ Copyright (C) 2015. By permission of Oxford University Press.

skills associated with clinical leadership in the future. This self-assessment tool could be used at a local level to assess the readiness of an individual personal attitude and understanding toward clinical leadership and governance in the future. Similarly, the self-assessment tool could be used to identify deficits in knowledge and learning requirements.

\section{To highlight the importance clinical leadership plays in the provision of quality care, improvement, and outcomes}

The Principles of Nursing Practice framework developed by the Royal College of Nursing $(\mathrm{RCN})^{21}$ highlight the importance leadership plays in delivering responsive, safe, quality, and compassionate care. McKenzie and Manley suggest that

$[\ldots]$ nurses and nursing staff lead by example develop themselves and other staff, and influence the way care is given in a manner that is open and responds to individual needs. ${ }^{10}$

Frampton indicated that "there is a need for strong, courageous leaders ... and everyone has leadership potential if they want it". ${ }^{8}$ Whilst agreeing with Frampton, we would go even further to say that, in our humble opinion, we must learn and share from the scandals of the Morecambe Bay and Mid Staffordshire NHS Foundation Trusts. ${ }^{2,3}$ Disinvesting in facilitating effective clinical leadership is at the peril of safety, quality, and governance, which will have devastating and immeasurable consequence for patients, carers, the public, health care workers, and the organizations themselves.

What is significant about the Kirkup ${ }^{2}$ and Mid Staffordshire NHS Foundation Trust ${ }^{3}$ scandals and other recent investigations and reviews, for example, Review into the Quality of Care and Treatment Provided by 14 Hospital Trusts in England: Overview Report ${ }^{22}$ is the distinct lack of authentic sustainable leadership and

[...] a significant disconnect between what the clinical leadership said were the key risks and issues and what was actually happening in wards and departments around the hospital. ${ }^{22}$

From our experiences, and in our opinion, there are some essential attributes associated with highlighting the importance that clinical leaders play in the provision of quality care, improvement, and outcomes.

The NHS Leadership Academy ${ }^{23}$, unlike us, makes inroads into illuminating and conceptualizing the personal attributes and qualities of an effective leader. "The Healthcare Leadership Model: Helping you to become a better leader" ${ }^{\prime 2}$ offer a sound framework to help facilitate this happening in practice.

Health care organizations need to identify, develop, and/or engage with leadership frameworks and/or program providers that suit their own unique health care organizational culture and working environment. We would argue that focusing on and applying the simple clinical leadership self-assessment tools and associated rationale may be one way of aligning and illustrating where clinical leaders' roles are in achieving existing governance and duty of candor systems and processes.

\section{Conclusion}

Given the global challenges facing clinical leaders, managers, educators, and researchers to provide safe, quality, 
compassionate care and services within financial constraints and targets. It is imperative that we do not disinvest in facilitating, resourcing, and supporting the development of aspiring and existing affective and effective clinical leaders in our wards, departments, and health care organizations in the future. Safe, quality care and services require clinical leaders who can challenge and be challenged to safeguard and protect their patients and staff. They need to be able to lead from the front, back, and the sides. Furthermore, clinical leaders require support, resources, education and training, reward and recognition, and external peer review by their health care organization to be both affective and effective. Health care organizational boards, managers and leaders, and staff need to familiarize themselves with what and why clinical leaders are important to quality, safety, and compassionate care. Essentially, it is about embracing the fact that we are all clinical leaders and custodians for safety, quality, and care for those entrusted to our care.

\section{Disclosure}

The authors report no conflicts of interest in this work.

\section{References}

1. McSherry R, Cottis K, Rapson T, Stringer M. Embracing external scrutiny to build bridges and genuine partnerships between education and clinical practice 2014. Nurs Educ Pract. 2014;15(3):149-154.

2. Kirkup B. The Report of the Morecambe Bay Investigation. The Stationery Office; 2015.

3. The Mid Staffordshire NHS Foundation Trust Public Inquiry. Report of the Mid Staffordshire NHS Foundation Trust Public Inquiry. Volume 3: Present and Future Annexes. London: The Stationery Office; 2013.

4. Slim in Leading in the NHS: A Practical Guide. 2nd ed. Stewart R, editor. London: Macmillan Business; 1996.

5. The King's Fund. The Future of Leadership and Management in the NHS: No More Heroes. London: The Kings Fund; 2011.

6. National Advisory Group on the Safety of Patients in England. A Promise to Learn - A Commitment to Act: Improving the Safety of Patients in England. London: National Advisory Group on the Safety of Patients in England; 2013

7. Cunnane D, Warwick R. Francis report: what went wrong with NHS leadership? The Guardian. February 14, 2013. Available from: http:/ www.theguardian.com/healthcare-network/2013/feb/14/francis-reportnhs-leadership. Accessed May 12, 2015.

8. Frampton L (2009) Changing culture on the frontline. Available from http://www.clinicalservicesjournal.com/story/5857/changing-cultureon-the-front-line. Accessed August 24, 2015.
9. McSherry R, Pearce P, Grimwood K, McSherry W. The pivotal role of nurse managers, leaders and educators in enabling excellence in nursing care. J Nurs Manag. 2012;20:7-19.

10. McKenzie C, Manley K. Leadership and responsive care: principle of Nursing Practice H. Nurs Stand. 2011;25(35):35-37.

11. Daly J, Jackson D, Mannix J, Davidson P, Hutchinson M. The importance of clinical leadership in the hospital setting. J Healthc Leadersh. 2014;6:75-83.

12. British Medical Association (BMA). Doctors' Perspectives on Clinical Leadership. London: BMA; 2012. Available from http://bma.org.uk/-/ media/files/pdfs/working\%20for\%20change/shaping\%20healthcare/ doctors $\% 20$ on $\% 20$ clinical $\% 201$ eadership $\% 20$ june $\% 202012$.pdf. Access August 24, 2015.

13. Stanley D. Recognising and defining clinical nurse leaders. Br J Nurs. 2006;15(2):108-111.

14. McSherry R, Pearce P. Clinical Governance: A Guide to Implementation for Healthcare Professionals. Oxford: Wiley-Blackwell Publishers; 2011.

15. McSherry R, Haddock J. Evidence-based healthcare: its place within clinical governance. Br J Nurs. 1999;8(2):113-117.

16. Bryson MJ. Strategic Planning for Public and Nonprofit Organizations: A Guide to Strengthening and Sustaining Organizational Achievement 4th ed. London: Wiley; 2011. Publishers London.

17. Ambrosini V, Johnson G, Scholes K. Exploring Techniques of Analysis and Evaluation in Strategic Management. Harlow: Pearson Education Limited; 1998.

18. Department of Health. Hard Truths: The Journey of Putting Patients First. London: HMSO; 2014. Available from https://www.gov.uk/government/ uploads/system/uploads/attachment_data/file/270368/34658_Cm_8777_ Vol_1_accessible.pdf. Accessed August 24, 2015.

19. Section 20: Duty of candour. In: The Health and Social Care Act 2008 (Regulated Activities) Regulations 2014 [webpage on the Internet]. 2014, London. Available from: http://www.legislation.gov.uk/ ukdsi/2014/9780111117613. Accessed May 12, 2015.

20. McSherry R. Quality of nursing care. In: McSherry W, McSherry R, Watson R, editors. Care in Nursing: Principles, Values and Skills. Oxford: Oxford University Press; 2012:33-46.

21. Manley K, Watts C, Cunningham G, Davis J. Principles of nursing practice: development and implementation. Nurs Stand. 2011;25(27): $35-37$.

22. Keogh B. Review into the Quality of Care and Treatment Provided by 14 Hospital Trusts in England: Overview Report. London: National Health Service; 2013. Available from: http://www.nhs.uk/nhsengland/ bruce-keogh-review/documents/outcomes/keogh-review-final-report. pdf. Accessed August 24, 2015.

23. NHS Leadership Academy. Clinical Leadership Competency Framework. Coventry: NHS Institute for Innovation and Improvement; 2011.

24. National Health Service Leadership Academy (2015) Healthcare Leadership Model: Helping you to become a better leader. Available from: http://www.leadershipacademy.nhs.uk/resources/healthcare-leadershipmodel/. Accessed August 24, 2015.
Journal of Healthcare Leadership

\section{Publish your work in this journal}

The Journal of Healthcare Leadership is an international, peer-reviewed, open access journal focusing on leadership for the health profession. The journal is committed to the rapid publication of research focusing on but not limited to: Healthcare policy and law; Theoretical and practical aspects healthcare delivery; Interactions between healthcare and society and evidence-based practices;

\section{Dovepress}

Interdisciplinary decision-making; Philosophical and ethical issues; Hazard management; Research and opinion for health leadership; Leadership assessment. The manuscript management system is completely online and includes a very quick and fair peer-review system. Visit http://www.dovepress.com/ testimonials.php to read real quotes from published authors. 